\title{
ACTINOMICOSE DO SISTEMA NERVOSO CENTRAL
}

\author{
UMA RARA COMPLICAÇAO DA ACTINOMICOSE CERVICOFACIAL
}

\author{
A. C. FERraZ *, C. V. M. MELO **, E. L. R. PEREIRA **, J. N. STAVALE ***。 \\ R. G. NOGUEIRA ****, A. A. GABBAI *, S. M. F. MALHEIROS *, \\ M. N. PRANDINI **, F. M. BRAGA $* *$
}

\begin{abstract}
RESUMO - A actinomicose do sistema nervoso central (SNC) é afecção rara, caracterizada pela formação de abscesso único e de evolução crônica. Os autores descrevem o caso de um paciente jovem, imunocompetente, com actinomicose cerebral oriunda de foco primário cervicofacial, submetido a ressecção cirúrgica e antibioticoterapia. Ressalta-se a importância do conhecimento da entidade e de suas principais formas de acometimento, como a base do diagnóstico precoce dessa enfermidade potencialmente curável e de bom prognóstico.
\end{abstract}

PALAVRAS-CHAVE: actinomicose, abscesso cerebral, diagnóstico, tratamento.

\begin{abstract}
Actinomycosis of the central nervous system: a rare complication of cervicofacial actinomycosis.
SUMMARY - Central nervous system actinomycosis is a rare but treatable chronic suppurative bacterial infection. The case of a young immunocompetent male with actinomycosis of the CNS is presented. The abscess originated from a primary cervico-facial infection and was located in the left parasellar region. After excision of the mass, that showed Actinomyces colonies, the patient was treated with intravenous Penicillin for 42 days followed by oral administration of the drug for 30 days. After surgery the patient was left with mild sequelae that had improved by the last follow-up, 7 months later. A new CT scan at that time revealed no residual disease or recurrence. The early diagnosis of cerebral actinomycosis relies essentially on a clinical suspicion. Hence it is imperative to be aware of the natural history of this infection and its various modes of presentation.
\end{abstract}

KEY WORDS: actinomycosis, brain abscess, diagnostics, treatment.

A actinomicose é infecção crônica caracterizada por supuração, formação de abscessos e trajetos fistulosos cutâneos múltiplos 13. Apresenta especial propensão para mimetizar uma série de enfermidades neoplásicas e inflamatórias $5,8,9,16,18$, principalmente nas fases iniciais, em que os sintomas e sinais são incaracterísticos. Esta particularidade torna o diagnóstico precoce extremamente difícil, fazendo com que menos de $10 \%$ dos pacientes recebam o diagnóstico correto à admissão hospitalar ${ }^{18}$. Estes dados enfatizam a necessidade de incluir a actinomicose no diagnóstico diferencial obrigatório das afeç̧ões cervicofaciais e cranianas e são o motivo da apresentação deste caso.

\section{RELATO DE CASO}

WM, um homem pardo, de 29 anos de idade, procedente de zona urbana do interior de São Paulo, padeiro, foi referido à Neurocirurgia do Hospital São Paulo em dezembro-1991, após

Escola Paulistia de Medicina: * Disciplina de Neurologia ; * Disciplina de Neurocirurgia; *** Departamento de Anatomia Patológica; **** Disciplina de Neuro-Radiologia. Aceite: 22janeiro-1993.

Dr. Joăo Norberto Stávale - Departamento de Anatomia Patológica, Escola Pauljsta de Medicina - 04023-900 São Paulo SP - Brasil. 
realização de trepłanação em outro Serviço. Relatava a seguinte história: há 2 anos apresentou dor dentária na arcada superior esquerda (E), acompanhada de aumento de volume na regiáo paramandibular do mesmo lado; realizada drenagem com agulha de possível abscesso nesta região. A dor persistiu e, alguns meses depois, a lesão estendeu-se à reglão temporal $\mathbf{E}$, seguida de aumento de volume e fistulização, com saída de material amarelado e grânulos. Nesta época começou a apresentar cefaléia holocraniana contínua, com piora progressiva, sem fatores acompanhantes e com alivio transitório com analgésicos comuns; realizou tomografia de crânio (TC) que mostrou, à E, aumento de partes moles em região temporal, hiperostose esfenoidal e temparal, perda da aeração em células mastóides e ouvido médio, imagem hiperdensa parasselar, com extensão para cisterna pré-pontina, realce homogêneo do contraste, sem edema ou efeito expansivo (Fig. 1). Realizada trepanação temporal E, com obtenção de tecido conjuntivo mostrando processo inflamatório crônico inespecífico. Referia desaparecimento da cefaléia após o procedimento.

Nove meses após a primeira cirurgia, procurou nosso Serviço; assintomático na cousião. Ao exame físico apresentava assimetria craniana às custas de abaulamento em região temporal E, cicatrizes em região piaramandibular $\mathbf{E}$ e dentes em péssimo estado de conservação. Estava afebril, sem adenomegalias e o exame físico e neurológico eram normais. Exames complementares - Hemoglobina 10,6g\%; leucócitos $6400 / \mathrm{mm} 3$, com $72 \%$ de segmentados, $27 \%$ de linfócitos e $1 \%$ de eosinófilos; plaquetas $453000 / \mathrm{mm}$. Bioquímica do sangue (incluindo dosagem de creatinina, uréia, sódio, potássio e glicose) normal. Radiografia de tórax e ultrassom de abdome sem anormalidades. Pesquisa de anticorpos contra HIV (método imunoenzimático) negativa. Submetido a craniotomia têmporo-parieto-frontal E, que revelou tumoração de consistência fibrosa, aderida à duna-máter, com extensão à fossa média e infiltração do osso subjacente e de estruturas do seio cavernoso. Realizada exérese parcial da lesăo. Evolução: no pós operatório notou-se acentuada diminuição da acuidade visual, proptose e paresía dos músculos extra-oculares inervados pelos terceiro e quarto nervos à E, anisocoria (díreita com $3,5 \mathrm{~mm}$ e esquerda com $2,5 \mathrm{~mm}$ ), semi-ptose e hipoestesia em hemiface E (ramos oftálmico e maxilar do $\mathrm{V}$ nervo). TC de crânio, 30 dias após, mostrou imagem de lesão residual extensa.

O exame anátomo-patológico mostrou, pela coloração Hematoxilina-Eosina, processo inflamatório crónico inespecífico, com focos supurativos, granulomas tipo corpo estranho e colónias de Actinomyces que se coraram positivamente para Gram (Fig. 2) e negativamente para ZiehlNielsen. O material não foi encaminhado para cultura. Iniciada antibioticoterapia com penicilina cristalina intravenosa na dose de 24 milhões de unidades por dia; nova TC de crânio, após 4 semanas de tratamento, mostrou imagem de aspecto semelhante à lesão residual pósoperatória. O déficit neurológico permaneceu estável; a antibioticoterapia endovenosa foi mantida até completar 6 semanas e o paciente recebeu alta com penicilina via oral. Uma TC de crânio e sela turca realizada 30 dias após a alta mostrou desaparecimento da imagem residual prévia; a antibioticoterapia foi suspensa nesta época. No sétimo mês de seguimento ambulatorial o paciente havia recuperado parte da acuidade visual e da motricidade dos músculos extra-oculares do olho E. Nova TC não mostrava sinais de recidiva da infecção.

\section{COMENTARIOS}

A actinomicose foi primeiramente descrita em 1877, quando Bollinger detectou filamentos ramificados em doença mandibular bovina; um ano depois, Harz os chamou de Actinomyces (fungos em forma de raio). O primeiro caso no ser humano foi descrito em 1878 por Israel 13,16. Suas principais formas de apresentação clínica incluem: 1) cervicofacial (em 46 a $63 \%$ dos casos nas diferentes séries); 2) abdominal $(22$ a $32 \%)$; e 3 ) torácica $(15 \text { a } 62 \%)^{13,18}$. O comprometi. mento do SNC é raro (menos de $4 \%$ dos casos) e deve sempre ser considerado secundário à disseminação hematogênica (em geral a partir de foco pulmonar ou dentário) ou por contiguidade a partir de focos cervicofaciais (seios paranasais, ossos, ouvido médio, mandíbula e face) 2,9,16,18. Bolton e Ashenhurst revisaram 18 casos comprovados por cultura e mostraram que 15 eram secundários a dissemiriação hematogênica a partir de foco dentário ou pulmonar 2. Smego estudou 70 casos publicados entre 1937 e 1987 e encontrou foco primário pulmonar em $27 \%$ dos casos, cervicofacial em $20 \%$, ouvido médio em $6 \%$, seios paranasais em $4 \%$, abdome em $6 \%$ e pelve em $4 \%$; em $30 \%$ dos casos o foco primário não foi identificado 16 .

Embora a maioria dos pacientes seja imunocompetente, cerca de $7 \%$ apresenta alguma doença debilitante ou imunossupressão de base 16,18; na literatura 
revisada só foi encontrado 1 caso associado à AIDS 19. Vários outros fatores predisponentes foram identificados: infecçōes e cáries dentárias, extração dentária recente, trauma craniano, cirurgias gastrointestinais, otite média e sinusite crônicas, osteomielite, uso de dispositivos intrauterinos e cardiopatias congênitas $3,7,16,18$.

Os abscessos cerebrais constituem a forma de acometimento mais comum e respondem por 60 a $70 \%$ dos casos de actinomicose no SNC. Em geral são são únicos e multilobulados, envolvem mais frequentemente os lobos temporal e frontal e possuem cápsula espessa e fibrosa. Evoluem de forma crónica, com sintomas que já duram mais de 1 mês à época da admissão (ao contrário dos outros abscessos bacterianos, que apresentam sintomas neurológicos com duração menor de 1 mês em $70 \%$ das vezes)2; o LCR apresenta padrões variáveis, podendo haver meningite linfomonocitária, com hiperproteinorraquia e glicose normal 2,3,8,16,18. Outras formas de acometimento do SNC incluem: meningite ou meningoencefalite (5 a $13 \%$ dos casos) e empiema subdural $(6 \%)^{2,16}$. Abscessos epidurais, osteomielite craniana e da coluna vertebral, lesões simulando tumores de fossa posterior e actinomicoma do gânglio de Gasser foram raramente descritos 1,4,10,14,16. Alguns casos de lesão actinomicótica supostamente primária e Ce localização intraventricular (III ventrículo) foram descritos 12, porém estudos mais recentes, com histoquímica e microscopia eletrónica, demonstraram que as estruturas consideradas hifas, na verdade, eram cistos colóides 14.

Etiologia - A actinomicose é causada por germes que constituem parte da flora normal da cavidade bucal, orofaringe e árvore traqueobrônquica. São bactérias Gram positivas anaeróbias da Ordem Actinimycetales. Estes organismos distinguem-se pela formação de filamentos com ramificação verdadeira ou micélios; esta característica morfológica fez com que fossem inicialmente classificados como fungos. Posteriormente, a partir de análises da parede celular e dos padrōes de sensibilidade antibiótica, foram definitivamente classificados como bactérias. Por muitos anos não se deu atenção à diferenciação etiológica dentro deste grupo de organismos morfologicamente relacionados, e o termo actinomicose era indistintamente aplicado a todas as afecções causadas pelos germes das familias Actinimycetaceae e Nocardiaceae. Porém, diferentes implicações clínicas e terapêuticas tornaram necessária a diferenciação destes dois agentes e atualmente reserva-se o termo actinomicose às infecções causadas pelas bactérias Actinomyces, mais frequentemente: A. israelli, A. bovis e A. odontolyticus 13,17. A nocardiose é processo infecccioso de origem exógena, subagudo, afetando primariamente os pulmões, com rápida disseminação hematogênica especlalmente para o SNC, que é acometido em cerca de $30 \%$ dos casos; a $\mathbf{N}$. asteróides é resistente à penicilina, sendo o tratamento de escolha realizado com sulfonamídicos 11,13,16. Na actinomicose, a infecção do SNC é constituída de flora mista em cerca de $30 \%$ dos casos; os organismos mais comuns são os estreptococos (aeróbicos e anaeróbicos), difteróides, coliformes e bacteróides 4,10,16.

Diagnóstico - Embora muitos autores exijam a identificação do organismo a partir de cultura 2, a maioria aceita a confirmação diagnóstica baseada em critérios histopatológicos 3,5,15-17. A demonstração dos grânulos actinomicóticos em cortes histológicos é considerada fortemente sugestiva de actinomicose. Pela coloração Hematoxilina-Eosina aparecem como massas com arranjo radiado de filamentos basofílicos no centro e terminações periféricas eosinofílicas (em forma de clavas); os organismos podem frequentemente ser vistos nesta coloração mas são melhor identificados pela coloração de Gram, como em nosso paciente (Fig. 2). O agente pode ser também identificado a partir de técnicas imuno-histoquímicas, usando anticorpos fluorescentes 6,16. A principal restrição quanto ao estabelecimento do diagnóstico em critérios puramente histológicos deve-se à difícil diferenciação com outras afeç̧ōes que também podem conter grânulos sulfúricos, entre elas: nocardiose, cromomicose e botriomicose $2,11,13,15,16$. Na maior parte das vezes porém, as características morfológicas e tintoriais distintas, como em nosso paciente, permitem a diferenciação 6,13,15,16.

Tratamento e prognóstico - A cura da actinomicose do SNC ocorre em 72 a $\mathbf{8 8 \%}$ dos pacientes tratados. O tratamento consiste em ressecção cirúrgica associada a antibioticoterapia em altas doses por tempo prolongado. A droga de escolha é a penicilina. Devido à presença de flora mista em 30\% dos casos de infecção do SNC, muitos preferem associar um segundo antibiótico de largo 


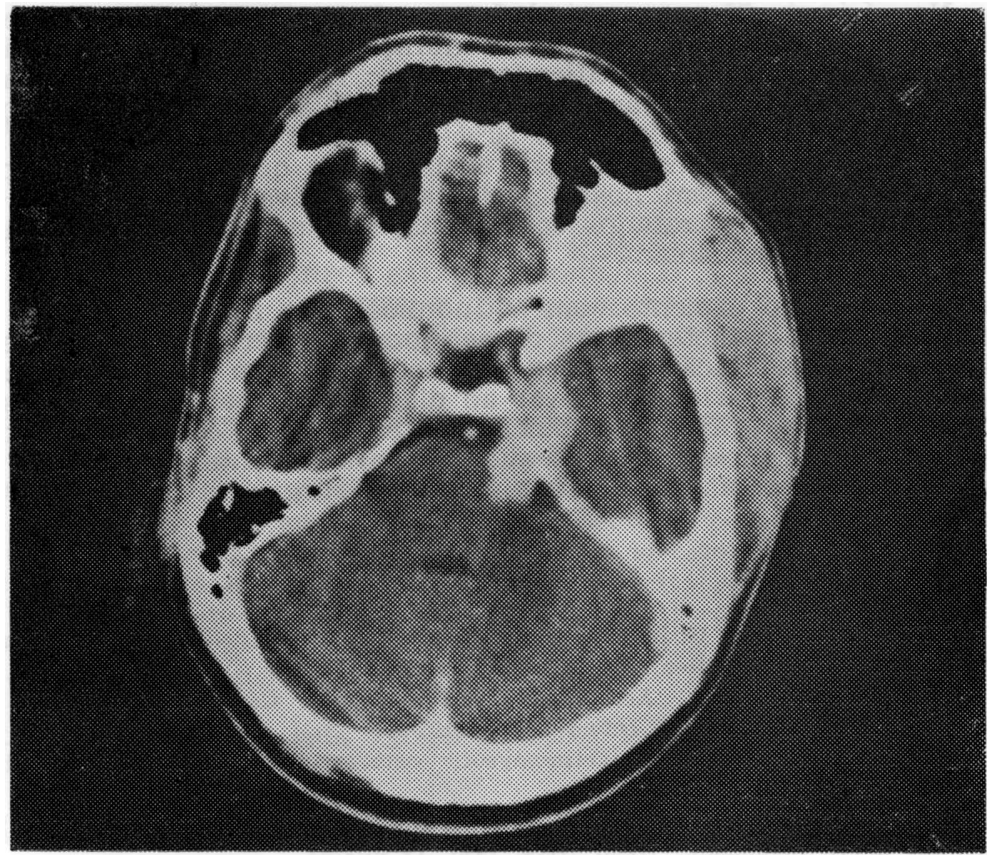

Fig. 1. Tomografia computadorlzada de cranto com injeça de contraste mostrando imagem de abscesso actinomicótico (vide texto).

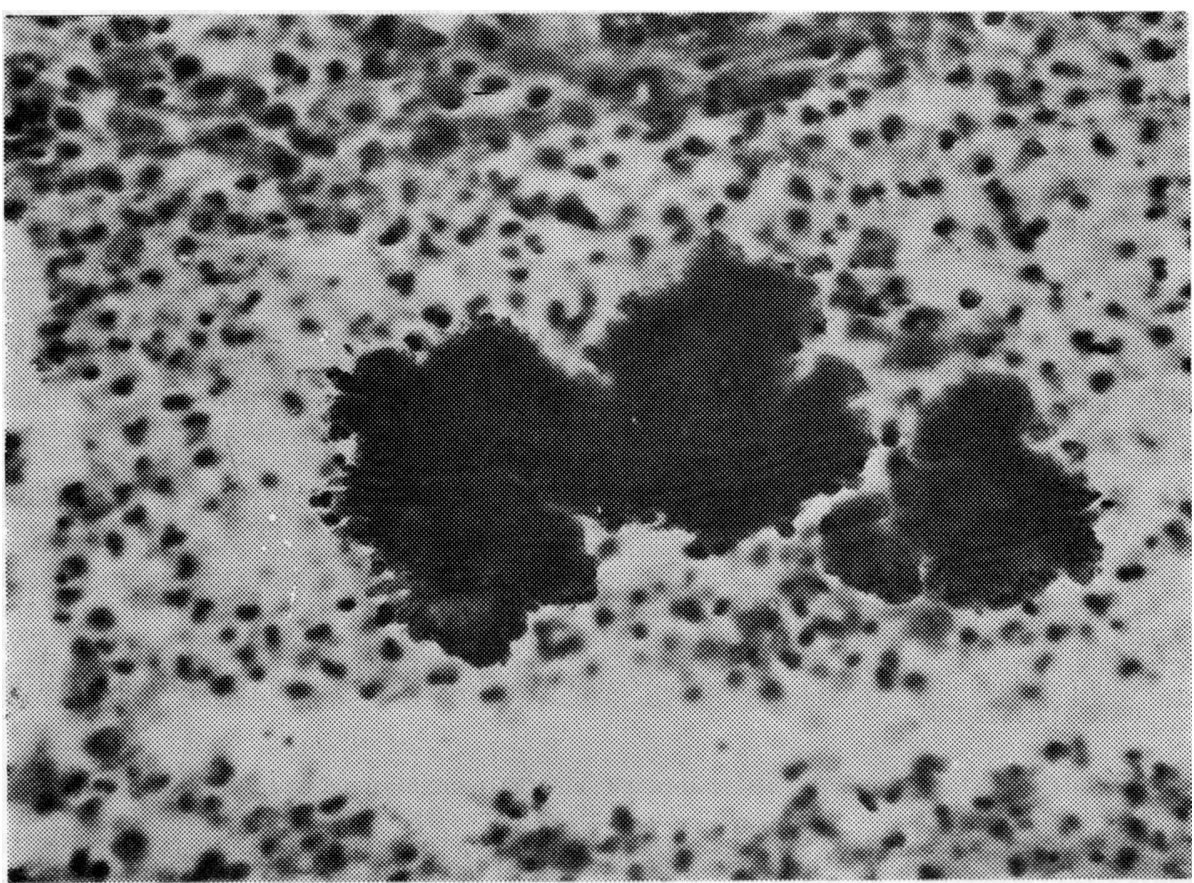

FIg. 2. Fotomlcrografla mostrando colónlas de Actinomyces em mefo a exsudato neutrofílico (abscesso). Na periferia das colônilas nota-se a característica distribuição em clavas (Gram; 400X). 
espectro. Na série de 70 casos estudada por Smego 13 , não houve diferença no prognóstico com relação ao tipo nem à duração do tratamento antibiótico; os fatores de mau prognóstico identificados foram: 1) duraçāo dos sintomas maior que 2 meses; 2) ausência de antibioticoterapia; 3) ausência de ressecção círúrgica. Sequelas ocorrem em cerca de 50\% dos casos tratados e estão mais frequentemente associadas à manipulação cirúrgica do que à doença propriamente dita 2,16,18, como ocorreu em nosso paciente. Recidivas são incomuns e foram descritas em raros casos tratados com drenagem por aspiração com agulha ou com ressecção cirúrgica isolada 2,16 .

Conclusão - No paciente com actinomicose do SNC descrito, as manifes tações iniciais foram características da actinomicose cervicofacial, representando forma típica de apresentação da doença. Neste caso, um alto índice de suspeita clínica teria sido necessário para levar ao diagnóstico mais precoce dessa enfermidade que, embora grave, é potencialmente curável, com bom prognóstico. Nosso paciente permaneceu com sequelas provavelmente pela longa evolução antes da antibioticoterapia e pela manipulação cinúrgica.

\section{REFERENCIAS}

1. Birley HDL, Teare EL, Utting JA. Actinomycotic osteomyelitis of the thoracic spine in a penicillin-sensitive patient. $J$ Infect 1989, 19:193-194.

2. Bolton CF, Ashenhurst EM. Actinomycosis of the brain. Can Med Ass J 1964, 90:922-938.

3. Burden P. Actinomycosis. J Infect 1989, 19:95-99.

4. Fewes LA, Laing RFC. Acute actinomycotic osteomyelitis of the skull with subdural empyema. J Infect 1990, 20:266-267.

5. Gady HE, Prager DA, Paix FS, Nash M. Actinomycotic granuloma masquerading as an infraorbital nerve neoplasm. Head Neck 1990, 12:261-263.

6. Hotchi M, Schwarz J. Characterization of actinomycotic granules by architecture and staining methods. Arch Path 1972, 93:392-400.

7. Ingham HR, Kalbag RM, Tharanmet D, High AS, Sengupta RP, Selkon JB. Abscesses of the frontal lobe of the brain secondary to covert dental sepsis. Lancet 1978, 2:497-499.

8. Khosla VK, Banerjee AK, Chopra JS. Intracranial actinomycoma with osteomyelitis simulating ineningioma. J Neurosurg 1984, 60:204-207.

9. Lerner PI. The lumpy jaw. Cervicofacial actinomycosis. Infect Dis Clin North Am 1988, 2:203-220.

10. Louie JA, Kusske JA, Rush JL, Pribram HW. Actinomycotic subdural empyema. J Neurosurg 1979, $51: 852-855$.

11. MeGinnis MR, Fader RC. Mycetoma: a contemporary concept. Infect Dis Clin North Am 1988, 2:939-954.

12. ORR TG Jr. Actinomycoma of the third ventricle, probably primary. JAMA 1945. 127: 757-758.

13. Peabody JW Jr, Seabury JH. Actinomycosis and nocardiosis. J Chron Dis 1957, 5:374-403.

14. Powers JM, Dodds FM. Primary actinomycoma of the third ventricle, the colloid cyst: 3 histochemical and ultrastructural study. Acta Neuropathol 1977, 37:21-26.

15. Robboy SJ, Vickery AL Jr. Tinctorial and morphologic properties distinguishing actinomycosis and nocardiosis. N Engl $J$ Med 1970, 282:593-596.

16. Smego RA, Actinomycosis of the central nervous system. Rev Infect Dis 1987, 9:855-865.

17. Waksman SA, Henrici AT. The nomenclature and classification of the Actinomycetes. J Bact 1943, 46:337-341.

18. Weese W, Smith IM. A study of 57 cases of actinomycosis over a 36-year period. Arch Intern Med 1975, 135:1562-1568.

19. Yager BA, Hoxie J, Weisman RA, Greenberg MS, Bilaniuk LT. Actinomycosis in the acquired immunodeficiency syndrome-relited complex. Arch Otolaryngol Head Neck Surg 1986, $112: 1293-1295$. 